\title{
Soluble CD73 as biomarker in patients with metastatic melanoma patients treated with nivolumab
}

\author{
Silvana Morello ${ }^{1 *} \mathbb{D}$, Mariaelena Capone ${ }^{2}$, Claudia Sorrentino ${ }^{1,3}$, Diana Giannarelli ${ }^{4}$, Gabriele Madonna², \\ Domenico Mallardo², Antonio M. Grimaldi², Aldo Pinto ${ }^{1 \dagger}$ and Paolo Antonio Ascierto ${ }^{2 \dagger}$
}

\begin{abstract}
Background: Nivolumab is an anti-PD1 checkpoint inhibitor active in patients with advanced melanoma and as adjuvant therapy in high-risk metastatic melanoma patients.

Methods: In this single-center retrospective analysis, we investigated the CD73 enzyme activity in patients with metastatic melanoma stage IV and its correlation with the response to nivolumab. The soluble CD73 (sCD73) enzyme activity was measured in the serum of 37 melanoma patients before receiving nivolumab and the Harrel's C index was used to find the best cut-off for this biomarker. The multivariate Cox proportional hazard model was used to evaluate the prognostic value of CD73 enzyme activity for survival and progression-free survival.

Results: Our results show that high levels of sCD73 enzyme activity were significantly associated with poor overall survival and progression-free survival in patients with metastatic melanoma. The median progression-free survival was 2.6 months [95\% confidence interval (CI) 1.9-3.3] in patients with high sCD73 enzyme activity (> 27.8 pmol/min/ mg protein), and 14.2 months (95\% Cl 4.6-23.8) in patients with lower CD73 enzyme activity, when patients were follow-up for a median of 24 months range. The median overall survival was not reached in patients with low sCD73 activity ( $<27.8 \mathrm{pmol} / \mathrm{min} / \mathrm{mg}$ protein) compared with 6.1 months (95\% Cl 0-14.8) in patients with higher sCD73 activity. In multivariate analyses, the sCD73 enzyme activity emerged as the strongest prognostic factor for overall survival and progression-free survival. Elevated basal levels of sCD73 enzyme activity, before starting nivolumab treatment, were associated with lower response rates to therapy.
\end{abstract}

Conclusions: We observed a significant association between the activity of sCD73 in the blood and clinical outcomes in patients with metastatic melanoma stage IV, receiving nivolumab. Although our results need to be confirmed and validated, we suggest that sCD73 might be used as serologic prognostic biomarker. Potentially evaluating sCD73 enzyme activity in the peripheral blood before treatment could help to estimate the response to nivolumab.

Keywords: Soluble CD73, Melanoma, Nivolumab, Immunotherapy, Biomarker

\section{Background}

Over the past years' treatment of metastatic melanoma has been revolutionized with immunotherapy, including inhibitors of modulatory receptors on T cells (also known as "immune checkpoints"), that are able to significantly

\footnotetext{
*Correspondence: smorello@unisa.it

${ }^{\dagger}$ Aldo Pinto and Paolo Antonio Ascierto equally contributed to this work

1 Department of Pharmacy, University of Salerno, Via Giovanni Paolo II

132, 84084 Fisciano, SA, Italy

Full list of author information is available at the end of the article
}

improve T-cell mediated immune response against cancer cells [1]. The first class of immune checkpoints approved by US Food and Drug Administration (FDA) for metastatic melanoma patients included an antibody anti-Cytotoxic $\mathrm{T}$ Lymphocyte Antigen-4 (CTLA-4) (ipilimumab), a co-inhibitory receptor expressed on the surface of T-cells. Ipilimumab is able to enhance T-cell proliferation and activation [2] and limit Tregs activity [3] inducing long-term regression of melanoma, although the therapeutic benefit of ipilimumab is limited to a small 
subset of patients [4-6]. Severe immune-related adverse events are common in patients receiving ipilimumab, and occasionally toxicity may cause severe morbidity or even mortality [7-10].

Programmed cell death protein-1 (PD-1) and its ligand PD-L1 are novel therapeutic immune checkpoint targets for cancer therapy [11]. PD-1 is a receptor expressed on CD4+T cells and CD8+ T cells that binds its ligands PD-L1 expressed on different cell types including tumor cells, or PD-L2 on macrophages and dendritic cells, inhibiting the function of T cells [12]. Nivolumab is an antibody anti-PD1 approved for the treatment of advanced melanoma patients for monotherapy and combination therapy [13-19]. Treatment of melanoma patients with nivolumab alone or in combination with ipilimumab has proved to induce an objective response rate (44-58\%) higher than ipilimumab alone and a significantly longer progression-free survival $[15,19,20]$. Grade 3 or 4 adverse events to nivolumab occur in $14.4 \%$ of patients, significantly lower than those observed in patients receiving ipilimumab (45.9\%); while $17.5 \%$ of patients experience any grade treatment-related effects [21]. Similar results were observed in patients with metastatic melanoma treated with pembrolizumab, a highly selective inhibitor of PD1, also approved for metastatic melanoma patients who progressed after ipilimumab or BRAF inhibitors treatment if appropriated [22, 23].

PD-L1 expression on melanoma cells, that was supposed to be required for response to nivolumab, appears to be associated to a more favourable response to PD1/ PD-L1 blocking antibodies [13, 24, 25]. However, the value of PD-L1 in melanoma as prognostic biomarker remains controversial because other studies have demonstrated that patients with PD-L1 negative tumours can also respond to anti-PD-1 pathway therapy [17, 26, 27]. Thus, the identification of biomarkers that correlates with rates of response to PD-1 blockade is a challenge for oncologists to define the subsets of patients who will likely benefit from this therapy $[28,29]$.

In this single-center retrospective study, we evaluated the association of sCD73 enzyme activity with clinical outcomes of patients with metastatic melanoma, receiving nivolumab. CD73, or ecto-5'-nucleotidase, is an enzyme which hydrolyses the extracellular AMP into adenosine, a potent anti-inflammatory mediator that critically impairs the anti-tumor immune response [30, 31]. CD73 is up-regulated in different types of human solid tumors (reviewed in Ref [32]). The over-expression of tumor CD73 is in general associated with worse overall survival or progression-free survival, as recently showed in a meta-analysis and systematic review conducted by Wang and collaborators [33]. CD73 is expressed on the surface of many cell types, including immune cells, endothelial cells, and tumor cells. Interestingly, recent data indicate that a soluble form of CD73 (sCD73) in the plasma also exists, and its levels are significantly increased in the plasma of cancer patients compared with healthy individuals [34, 35], as well as in patients with acute inflammatory pancreatitis [36].

Here, we observed that melanoma patients stage IV with elevated basal serum level of sCD73 enzyme activity, before starting nivolumab treatment, had a lower response rate to nivolumab, shorter survival and higher rates of progression of disease. Patients obtaining partial response (PR) to nivolumab or stable disease had low levels of sCD73 activity in the serum, thus suggesting a predictive role for $\mathrm{SCD} 73$. Although it is far from a validated predictive biomarker, plasma sCD73 enzyme activity could play a role in defining the subsets of patients who will benefit from a therapy with nivolumab.

\section{Methods}

\section{Patients characteristics}

This retrospective single-center study included a total of 37 patients (male, $\mathrm{n}=21$; female $\mathrm{n}=16$ ) aged $>18$ years with metastatic stage IV melanoma and samples were collected between January 1st 2015 and December 31st 2016 at the Department of Melanoma, Cancer Immunotherapy and Innovative Therapies Unit. $\mathrm{N}=13$ patients of 37 patients (35\%) had BRAF V600-mutant melanoma, $\mathrm{n}=19$ patients $(51 \%)$ were wild-type for BRAF, while $\mathrm{n}=5$ patients included in this study had unknown BRAF status. 27/37 patients (73\%) did not present brain metastases, while $\mathrm{n}=7$ patients $(19 \%)$ had brain metastases. $\mathrm{N}=24$ patients $(65 \%)$ had M1c disease and $\mathrm{n}=19$ (51\%) had an elevated lactate dehydrogenase level (LDH > 480 International Units [IU]/L). Nivolumab at the dosage of $3 \mathrm{mg} / \mathrm{kg}$ was administered in patients who had previously received ipilimumab alone or in combination with a BRAF inhibitor ( $\mathrm{n}=7$ patients), every 2 weeks until disease progression or unacceptable toxicity appeared. Tumor response was evaluated at 12 weeks and then every 12 weeks until progression or the discontinuation of treatment according to the Response Evaluation Criteria In Solid Tumors (RECIST), version1.1. The overall response rate (ORR) to nivolumab was 24\% (9/37: 0 patients with complete response $[\mathrm{CR}]$ and 9 patients with partial response). The disease control rate (DCR) to nivolumab was 46\% (17/37: 0 patients CR, 9 PR and 8 with stable disease [SD]). $46 \%$ of patients (17/37) showed progressive disease (PD); while 3 patients died before the assessment of response to treatment.

\section{CD73 enzyme activity}

The CD73 enzyme activity of hydrolysing AMP to adenosine and inorganic phosphate was determined in sera by 
measuring the concentrations of inorganic phosphate $(\mathrm{P} i)$ with the Malachite Green assay kit (CliniSciences, Italy), as previously described [37-39]. Serum was obtained from blood sample of each patients withdrawn before starting nivolumab treatment. Briefly, serum samples $(100 \mu \mathrm{g}$ of proteins) were incubated in assay medium containing $\mathrm{MgCl}_{2}(10 \mathrm{Mm}), \mathrm{NaCl}(120 \mathrm{mM})$, $\mathrm{KCl}(5 \mathrm{mM})$, glucose $(60 \mathrm{mM})$, Tris- $\mathrm{HCl}(50 \mathrm{mM}), \mathrm{pH}$ 7.4 for $10 \mathrm{~min}$. AMP ( $2 \mathrm{mM})$ was added as substrate and samples kept at $37^{\circ} \mathrm{C}$ for $40 \mathrm{~min}$. To stop the reaction trichloroacetic acid (TCA, final concentration $5 \% \mathrm{w} / \mathrm{v}$ ) was added. The concentration of inorganic phosphate $(\mathrm{P} i)$ released during the hydrolysis of AMP was measured using the Malachite Green assay according to the manufacturer's instructions. To have the net value of P $i$ produced following enzymatic reaction, aspecific $\mathrm{P} i$ released in absence of AMP in each sample was subtracted from the value obtained following incubation with AMP. To determine specificity, experiments were also performed in the presence of the CD73 inhibitor, adenosine 5'-(a,bmethylene) diphosphate (APCP; Tocris Bioscience, Bristol, U.K.) $(40-100 \mu \mathrm{M})$, which is a non-hydrolysable ADP analogue. For these experiments, samples were incubated with APCP in assay medium for $30 \mathrm{~min}$ at $37^{\circ} \mathrm{C}$ before adding AMP. All samples were run in triplicate; results were expressed as $\mathrm{P} i$ released ( $\mathrm{pmol} / \mathrm{min} / \mathrm{mg}$ protein). All reagents, as not indicated otherwise, were from SigmaAldrich S.r.l. (Milan, Italy).

\section{Statistical analysis}

Differences in sCD73 enzyme activity values across patients' characteristics were evaluated with the MannWhitney non parametric test. Chi square test was used to study associations among categorical variables. Survival curves were estimated with the Kaplan-Meier method and differences evaluated with the log-rank test. Associations between CD73 values and survival times were measured with the Harrel'c index. Best cut-off values were located with an $\mathrm{R}$ routine implemented on the online software (Cut-off Finder) which maximize differences in survival between the two groups. Hazard Ratios (HR) and their 95\% confidence intervals (95\% CI) were calculated using the proportional hazard model. Multivariate analysis was performed to identify independent factors associated with survival times.

\section{Results}

\section{sCD73 enzymatic activity in patients with metastatic melanoma}

In this study we retrospectively analysed the basal levels of soluble CD73 (sCD73) enzyme activity in the serum samples of patients with metastatic melanoma, before starting nivolumab treatment. The median enzyme activity of sCD73 was analysed in relationship to gender, age, BRAF status (wild-type versus mutated), brain metastases, LDH levels and number of previous therapy line, as summarized in Table $1.70 \%$ of the patients presented detectable CD73 enzyme activity; whilst some samples presented no detectable CD73 enzyme activity. Elevated sCD73 activity was associated with male gen$\operatorname{der}(P=0.007)$, but not with other variables (Table 1$)$. Indeed, patients with BRAF V600-mutant melanoma had values of sCD73 enzyme activity similar to those measured in BRAF wild-type melanoma $(\mathrm{P}=0.99)$ (Table 1$)$. No significant differences in the activity of sCD73 was found between patients with or without brain metastases $(P=0.84)$, in patients with normal LDH versus patients with elevated $L D H$ values $(P=0.11)$, or in relationship to the number of previous line of treatment $(\mathrm{P}=0.28)$ (Table 1).

To determine the specificity of the reaction, samples with the highest sCD73 enzyme activity were incubated with the non-hydrolysable inhibitor of CD73, APCP (40-100 $\mu \mathrm{M})$ before adding the substrate AMP. APCP significantly reduced the accumulation of $\mathrm{P} i$ in a concentration-dependent manner [from $87.337 \pm 27.995$ to $55.00 \pm 38.658 \mathrm{pmol} / \mathrm{min} / \mathrm{mg}$ protein (APCP, $40 \mu \mathrm{M}$ ) and to $1.375 \pm 2.428 \mathrm{pmol} / \mathrm{min} / \mathrm{mg}$ protein $(\mathrm{APCP}, 100 \mu \mathrm{M})$; $\mathrm{n}=4, \mathrm{P}<0.05$ Mann-Whitney U test] (Fig. 1).

Table 1 sCD73 activity in metastatic melanoma patients

\begin{tabular}{lccc}
\hline & $\mathbf{n}$ & $\begin{array}{l}\text { SCD73 activity pmol/min/mg } \\
\text { protein [median (range) }\end{array}$ & P value $^{\mathbf{a}}$ \\
\hline $\begin{array}{l}\text { Gender } \\
\text { Male }\end{array}$ & 21 & $26.7(0.0-255.3)$ & 0.007 \\
$\quad$ Female & 16 & $0.0(0.0-75.8)$ & \\
Age (years) & & & 0.16 \\
$<62$ & 18 & $21.9(0.0-93.7)$ & \\
$\geq 62$ & 19 & $6.4(0.0-255.3)$ & 0.99 \\
BRAF status & & & \\
Wt & 19 & $16.5(0.0-90.9)$ & 0.84 \\
Mutated & 13 & $13.9(0.0-255.3)$ & \\
Brain mets & & & \\
Yes & 7 & $16.0(0.0-90.9)$ & \\
No & 27 & $13.9(0.0-255.3)$ & \\
LDH (IU/L) & & & 0.11 \\
$<480$ & 17 & $7.2(0.0-90.9)$ & \\
$>480$ & 19 & $25.2(0.0-255.3)$ & \\
N of previous therapy line & & \\
2 & 24 & $10.0(0.0-93.7)$ & $19.5(0.0-255.3)$ \\
$>2$ & 12 &
\end{tabular}

WT wild-type, mets: metastasis, $L D H$ lactate dehydrogenase, IU/L International Units per Liter, $N$ number

${ }^{a}$ Mann-Whitney $U$ test 


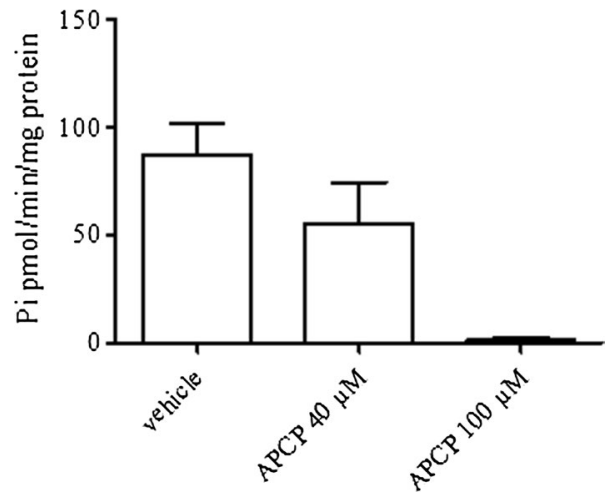

Fig. 1 The activity of CD73 in hydrolysing AMP was inhibited in presence of the CD73 inhibitor APCP (40-100 $\mu \mathrm{M})$. APCP was added to the samples before adding the substrate AMP. Data are mean \pm S.E.M

\section{sCD73 enzymatic activity and survival}

In order to investigate the association between sCD73 enzymatic activity values and overall survival and progression-free survival Harrel's $C$ index was calculated. These values showed a good association $\mathrm{c}=0.68(0.45-$ $0.92)$ for overall survival and $\mathrm{c}=0.65(0.44-0.85)$ for progression-free survival.

To establish the sensitivity and specificity of sCD73 enzyme activity thresholds for survival the optimal cutoff value was calculated. The optimal cut-off of sCD73 activity for both overall survival and progression-free survival was $27.82 \mathrm{pmol} / \mathrm{min} / \mathrm{mg}$ protein, as determined by Cut-off Finder online software (Fig. 2). Among patients with metastatic melanoma analysed in this study, 27/37 (73\%) patients showed a cut-off value of $\mathrm{sCD} 73<27.8 \mathrm{pmol} / \mathrm{min} / \mathrm{mg}$ protein and 10/37 (27\%) patients with sCD73 $>27.8 \mathrm{pmol} / \mathrm{min} / \mathrm{mg}$ protein.

Median overall survival was not reached in patients with low values of sCD73 enzyme activity $(<27.82 \mathrm{pmol} /$

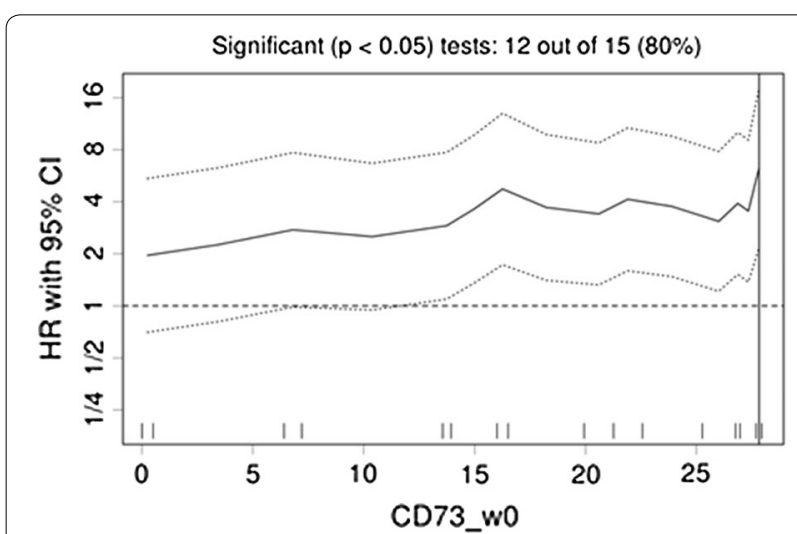

Fig. 2 Hazard ratio (HR) and 95\% confidence intervals (CI) according to different values of basal CD73 enzyme activity $\mathrm{min} / \mathrm{mg}$ protein) compared with 6.1 (95\% CI 0-14.8) months for patients with elevated sCD73 enzyme activity (> $27.82 \mathrm{pmol} / \mathrm{min} / \mathrm{mg}$ protein) (Fig. 3a; $\mathrm{P}<0.0001$ ), when patients were follow-up for a median of 24 months. Median progression-free survival was 14.2 months (95\% CI 4.6-23.8) in patients with low sCD73 enzyme activity $(<27.82 \mathrm{pmol} / \mathrm{min} / \mathrm{mg}$ protein) and 2.6 months $(95 \% \mathrm{CI}$ 1.9-3.3) in patients with sCD73 enzyme activity higher than $27.82 \mathrm{pmol} / \mathrm{min} / \mathrm{mg}$ protein (Fig. $3 \mathrm{~b} ; \mathrm{P}=0.001$ ).

\section{sCD73 enzyme activity as possible prognostic factor in metastatic melanoma}

Serum lactate dehydrogenase (LDH) is one of the most important recognized independent prognostic factor in melanoma patients with stage IV disease [40]. In line with this, univariate logistic regression was performed to evaluate the impact of gender, age, BRAF status, LDH levels, line of treatment, brain metastasis or basal activity of sCD73 on response to nivolumab. Elevated LDH levels were found to be significantly associated with worse overall survival and progression-free survival among the patients of this study (Tables 2, 3, respectively). The number of previous treatment also impacts on progression-free survival (Table 3). Interestingly, we observed that patients with high basal sCD73 enzyme activity ( $>27.8 \mathrm{pmol} / \mathrm{min} / \mathrm{mg}$ protein) had six- and four-fold increased risk of death and progression, respectively, when compared with patients with sCD73 enzyme activity $<27.8 \mathrm{pmol} / \mathrm{min} / \mathrm{mg}$ protein $(\mathrm{HR}=6.27 ; 95 \% \mathrm{CI}$ 2.17-18.11; $\mathrm{P}=0.001$ and $\mathrm{HR}=4.24 ; 95 \% \mathrm{CI} 1.64-10.93$; $\mathrm{P}=0.003$, respectively) (Tables 2,3 , respectively).

At multivariate analysis, sCD73 enzyme activity remained the only factor associated with survival, both overall and progression-free $(\mathrm{HR}=6.27$; $95 \% \mathrm{CI} 2.17$ $18.11 ; \mathrm{P}=0.001$ ) (Tables 2,3 , respectively).

\section{The sCD73 enzyme activity correlates with clinical} response to nivolumab in metastatic melanoma patients We next found that there is also an association between the response of patients to nivolumab and the value of the enzyme activity of sCD73 measured in the serum before treatment with nivolumab, compared with patients who do not respond to treatment. All patients considered in this study who showed a PR to nivolumab or stable disease (SD) had low levels of sCD73 enzyme activity before starting the treatment (Table 4). Accordingly, the DCR to nivolumab, defined as the proportion of patients with $\mathrm{CR}, \mathrm{PR}$ and $\mathrm{SD}$, was significantly associated with low pretreatment sCD73 enzyme activity $(<27.8 \mathrm{pmol} / \mathrm{min} / \mathrm{mg}$ protein) $(\mathrm{P}=0.001)$ (Table 4$)$. Conversely, almost half of the patients who progressed (PD) after nivolumab treatment had elevated basal sCD73 enzyme activity (Table 4 ). 

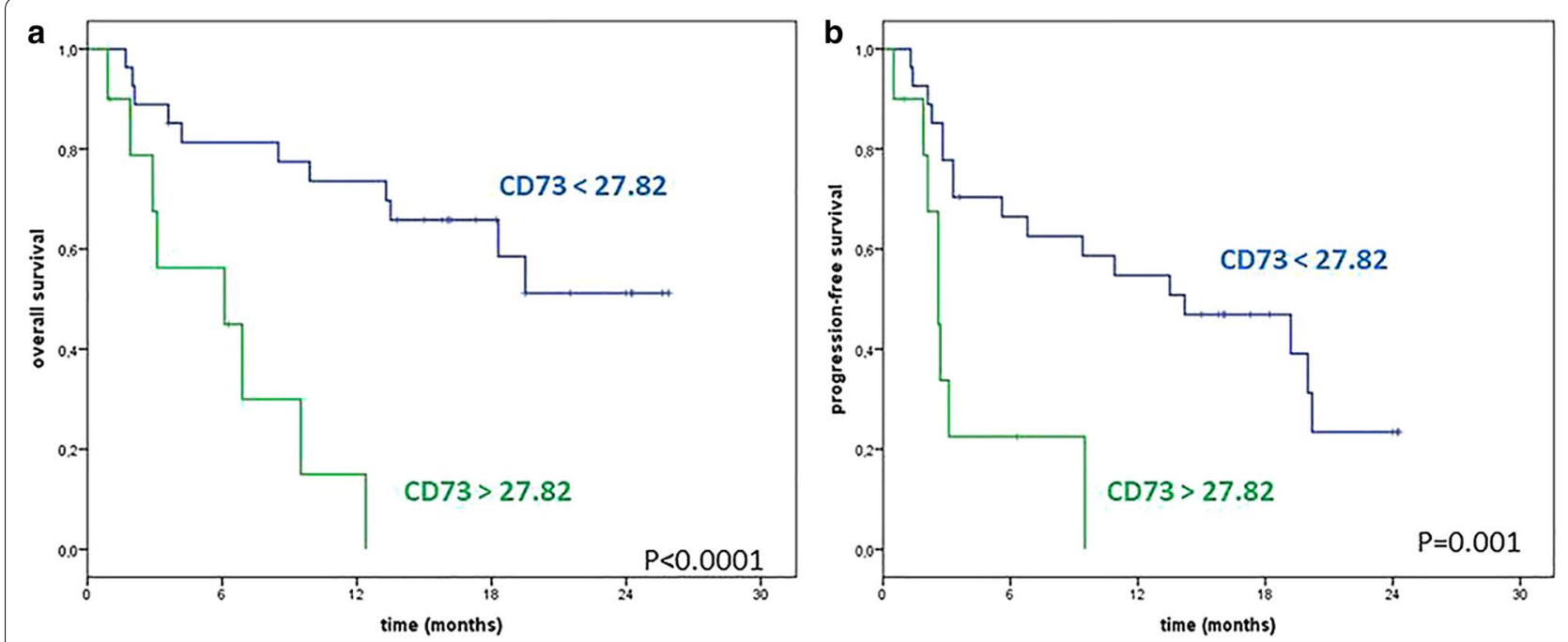

Fig. 3 Kaplan-Meier 24-months curves of overall survival (OS; a) and progression-free survival (PFS; b) of metastatic melanoma patients treated with nivolumab, according to basal sCD73 enzyme activity. Blue line: $\mathrm{CD} 73<27.8 \mathrm{pmol} / \mathrm{min} / \mathrm{mg}$ protein; green line: $\mathrm{CD} 73>27.8 \mathrm{pmol} / \mathrm{min} / \mathrm{mg}$ protein

Table 2 Analyses of the associations of sCD73 activity and overall survival

\begin{tabular}{|c|c|c|}
\hline & $\begin{array}{l}\text { Univariate } \\
\mathrm{HR}(95 \% \mathrm{Cl}) \mathrm{P} \text { value }\end{array}$ & $\begin{array}{l}\text { Multivariate } \\
\text { HR }(95 \% \mathrm{Cl}) \mathrm{P} \text { value }\end{array}$ \\
\hline Gender (M vs. F) & $2.08(0.80-5.38) P=0.13$ & n.s. \\
\hline Age, years ( $\geq 62$ vs. $<62$ ) & $1.09(0.45-2.65) P=0.85$ & n.s. \\
\hline BRAF status (mut vs. wt) & $0.53(0.19-1.48) P=0.22$ & n.s. \\
\hline $\mathrm{LDH}, \mathrm{IU} / \mathrm{L}(\geq 480$ vs. $<480)$ & $2.72(1.07-6.88) P=0.03$ & n.s. \\
\hline Line of treatment (> 2 vs. 2) & $2.38(0.96-5.94) P=0.06$ & n.s. \\
\hline Brain METS (yes vs. no) & $1.04(0.35-3.12) P=0.94$ & n.s. \\
\hline Basal sCD73 activity ( $\geq 27.8$ vs. $<27.8)$ & $6.27(2.17-18.11) P=0.001$ & $6.27(2.17-18.11) P=0.001$ \\
\hline
\end{tabular}

$H R$ hazard ratio, $C I$ confidence interval, $n . s$. not significant, $M$ male, $F$ female, $M U T$ mutant, $W T$ wild-type, $L D H$ lactate dehydrogenase, IU/L International Units per Liter, METS metastasis, $S C D 73$ soluble CD73

$P$ values are from Cox proportional hazard Regression models

Table 3 Analyses of the associations of sCD73 activity and progression-free survival

\begin{tabular}{|c|c|c|}
\hline & $\begin{array}{l}\text { Univariate } \\
\mathrm{HR}(95 \% \mathrm{Cl}) \mathrm{P} \text { value }\end{array}$ & $\begin{array}{l}\text { Multivariate } \\
\text { HR }(95 \% \mathrm{Cl}) \mathrm{P} \text { value }\end{array}$ \\
\hline Gender (M vs. F) & $1.64(0.73-3.70) P=0.23$ & n.s. \\
\hline Age, years ( $\geq 62$ vs. $<62$ ) & $1.30(0.59-2.89) P=0.52$ & n.s. \\
\hline BRAF status (mut vs. wt) & $0.72(0.30-1.69) P=0.45$ & n.s. \\
\hline LDH, IU/L ( $\geq 480$ vs. < 480) & $2.37(1.04-5.39) P=0.04$ & n.s. \\
\hline Line of treatment (> 2 vs. 2) & $2.34(1.02-5.34) P=0.04$ & n.s. \\
\hline Brain METS (yes vs. no) & $1.33(0.53-3.36) P=0.54$ & n.s. \\
\hline Basal sCD73 activity ( $\geq 27.8$ vs. $<27.8)$ & $4.24(1.64-10.93) P=0.003$ & $4.24(1.64-10.93) P=0.003$ \\
\hline
\end{tabular}

$H R$ hazard ratio, $C I$ confidence interval, n.s. not significant, $M$ male, $F$ female, $M U T$ mutant, WT wild-type, LDH lactate dehydrogenase, IU/L International Units per Liter, METS metastasis, $S C D 73$ soluble CD73

P values are from Cox proportional hazard Regression models 
Table 4 Response to treatment related to sCD73 enzyme activity levels

\begin{tabular}{|c|c|c|c|}
\hline & $\mathrm{sCD} 73<27.8 \mathrm{pmol} / \mathrm{min} / \mathrm{mg}$ protein & $\mathrm{sCD73}>27.8 \mathrm{pmol} / \mathrm{min} / \mathrm{mg}$ protein & Pts \\
\hline$C R$ & - & - & 0 \\
\hline PR & $9(100 \%)$ & 0 & 9 \\
\hline SD & $8(100 \%)$ & 0 & 8 \\
\hline PD & $9(52.9 \%)$ & $8(47.1 \%)$ & 17 \\
\hline $\begin{array}{l}D C R \\
(C R+P R+S D)\end{array}$ & 17 (100\%) & 0 & 17 \\
\hline
\end{tabular}

Pts patients, $C R$ complete response, $P R$ partial response, $S D$ stable disease, $P D$ progressive disease, $D C R$ disease control rate

These results suggest that elevated serum levels of sCD73 enzyme activity could be a negative predictor of response to nivolumab therapy.

\section{Discussion}

Nivolumab and other monoclonal antibodies against PD1/PD1L pathway represent the most effective therapeutics in advanced melanoma to date. The identification of biomarkers that predict the clinical response to antiPD1 drugs still remains a challenge for selecting patients for therapy.

This study provides preliminary evidence of a significant association between the activity of sCD73 and clinical outcomes in patients with metastatic melanoma stage IV, including overall survival and progression-free survival. Patients with elevated serum sCD73 enzyme activity had a significantly increased risk of death and disease progression compared to patients with low CD73 enzyme activity. Interestingly, we observed that the basal activity of sCD73 in the serum, determined before starting nivolumab therapy, is elevated in patients who do not respond to nivolumab treatment, while patients who benefit from nivolumab treatment had lower levels of sCD73 enzyme activity.

High expression of CD73 has been found in melanoma cell lines, associated with an invasive phenotype [41, 42] and metastasis-promoting antigens [43]. In malignant melanoma expression of CD73 is epigenetically regulated and methylation in the NT5E (CD73) CpG island is associated with high risk of metastasis to brain and visceral sites [44]. Very recently, although elevated tumor levels of CD73 have been found in melanoma patients with late-stage disease [45], the expression of CD73 within tumor microenvironment is heterogeneous in primary melanomas and cutaneous melanoma metastases [42], raising the question whether immunohistochemical analysis of CD73 may be a valuable prognostic factor in melanoma. Here, detectable sCD73 enzyme activity was found in the peripheral blood of $70 \%$ of the patients with stage IV melanoma and elevated levels of CD73 enzyme activity were associated with worse overall survival and progression-free survival. In the population of patients reported in this study the levels of sCD73 enzyme activity were not associated with the status of BRAF (mutated versus wild-type), the presence or not of brain metastasis, or the levels of LDH. In addition, we did not observe any significant difference in the basal sCD73 enzyme activity levels between patients previously treated with ipilimumab and those treated with BRAF inhibitors if indicated. To the best of our knowledge, this is the first observation that the activity of sCD73 determined in the peripheral blood of melanoma patients may have a value as prognostic factor, and although these results need to be confirmed and validated in larger randomized studies, they would suggest that prospectively CD73 could be used as serologic biomarker, in addition to known clinical prognostic parameters on multivariate analysis in patients with advanced melanoma. A validation in external populations, that is in progress, may also help to establish the best definitive cut-off reference for sCD73 activity-positive status and its specificity for metastatic melanoma. Nonetheless, elevated levels of sCD73 activity and expression have been found also in the serum of patients with other types of tumors [34, 35]. Perhaps, the increased levels of sCD73 in the serum might have a prognostic value extending beyond melanoma to other cancers, and it could complement the prognostic value of other biomarkers or histopathologic features to guide also the selection of patients for therapy.

Increased levels of sCD73 in the serum may probably reflect an elevated expression of CD73 within tumor microenvironment in cancer patients, most likely as consequence of tissue-associated inflammation/hypoxia [46] and possibly it may be useful to direct patients for treatment with CD73/adenosine pathway-targeted therapies. However, whether CD73 in the peripheral blood correlates with its expression in the tumor microenvironment or even with the degree of $\mathrm{T}$ cells infiltration and/or PD-L1 expression remains unknown.

Changes in tumor CD73 expression has been recently seen in BRAF-mutant melanoma patients receiving BRAF/MEK inhibitors and in BRAF-mutant melanoma 
cell lines [42, 45, 47]. Almost half of the patients treated with BRAF/MEK inhibitors showed decreased tumor CD73 expression [42, 45]. Conversely, an up-regulation on-treatment of tumor CD73 expression has been found in a subset of melanoma patients who, in most cases, had progressed after pembrolizumab therapy or MART-1 adoptive $T$ cell transfer therapy, suggesting a possible mechanism of drug acquired resistance [42]. It is important therefore to establish in future studies whether there is any correlation between the enzymatic activity of sCD73 in the peripheral blood of patients with advanced melanoma and clinical outcomes following PD-1 blockade regardless the treatment; or whether sCD73 enzyme activity in the serum could change after receiving PD1 blocking antibodies and if this value could be still associated with response rate (regardless the changes of CD73). Studies to solve this issue are in progress.

Numerous pre-clinical studies have demonstrated that adenosinergic pathway-targeted therapies can significantly reduce tumor growth and metastasis, improving the T-cell-mediated anti-tumor response [48-52] and synergize with antibodies anti-PD1 and anti-CTLA4 [53-56], establishing the bases for ongoing clinical trials [NCT02503774 and NCT02655822]. In this study, we found that the activity of sCD73 determined in the serum before treatment with nivolumab is inversely associated with objective response to nivolumab, leading us to suggest this marker as possible candidate to discriminate responders to non-responders. Non-responders to nivolumab show high levels of sCD73 activity in serum before treatment, raising the questions whether these patients would benefit from immune checkpoint inhibitors whenever associated with CD73 inhibitors.

\section{Conclusions}

In conclusion we found that the sCD73 enzyme activity in the peripheral blood of melanoma patients may be a potential prognostic factor. The sCD73 enzyme activity, measured before starting treatment, correlates with clinical response to nivolumab. Validation of these results would support the value of sCD73 as predictive biomarker of response to nivolumab therapy, useful to define the subsets of patients who will likely benefit from immunotherapies and possible provide additional treatment target (CD73) in combination with immunotherapeutic agents.

\footnotetext{
Abbreviations

sCD73: soluble CD73; CTLA-4: cytotoxic T lymphocyte antigen-4; PD-1: programmed cell death protein-1; ORR: overall response rate; CR: complete response; PR: partial response; SD: stable disease; PD: progressive disease; DCR: disease control rate; $\mathrm{Cl}$ : confidence interval; HR: hazard ratios; Pi: inorganic phosphate; APCP: adenosine 5'-(a,b-methylene) diphosphate; PTS: patients;
}

WT: wild-type; MUT: mutant; METS: metastasis; LDH: lactate dehydrogenase; IU/L: international units per liter.

\section{Authors' contributions}

SM conceived the study. SM, AP and PAA designed the work. SM wrote the manuscript. SM, MC, CS, DG, DM and AMG acquired the samples, performed the experiments and acquired the data. SM, DG, AP and PAA analysed the data. SM, DG, AP and PAA discussed results and implications of findings. All authors read and approved the final manuscript.

\section{Author details \\ 1 Department of Pharmacy, University of Salerno, Via Giovanni Paolo II 132, 84084 Fisciano, SA, Italy. ${ }^{2}$ Melanoma, Cancer Immunotherapy and Innova- tive Therapies O.U, National Cancer Institute "G. Pascale", Naples, Italy. ${ }^{3} \mathrm{PhD}$ Program in Drug Discovery and Development, University of Salerno, Fisciano, SA, Italy. ${ }^{4}$ Regina Elena National Cancer Institute, Rome, Italy.}

\section{Acknowledgements \\ Not applicable.}

\section{Competing interests}

Paolo A. Ascierto (PAA) has/had a consultant/advisory role for BMS, RocheGenentech, MSD, Array, Novartis, Amgen, Merck Serono, Pierre Fabre, Incyte. He also received research funds from BMS, Roche-Genentech and Array. He is also Section Editor for Combination Strategies for Journal of Translational Medicine. Antonio M Grimaldi (AMG) received honoraria from BMS, MSD, Novartis and Roche Genentech, and had consultant/advisory role for MSD and Novartis. The other authors declare they have no competing interests.

\section{Availability of data and materials}

All data generated and analysed during the current study are included in this published article.

\section{Consent for publication}

All the patients provided written informed consent.

\section{Ethics approval and consent to participate}

This study was approved by a local ethics committee (National Cancer Institute of Naples, Reference Number CO-2011-02348049) in compliance with Helsinki Declaration.

Funding

This work was supported by FARB 2016 (University of Salerno).

\section{Publisher's Note}

Springer Nature remains neutral with regard to jurisdictional claims in published maps and institutional affiliations.

Received: 23 September 2017 Accepted: 21 November 2017

Published online: 04 December 2017

\section{References}

1. Pardoll DM. The blockade of immune checkpoints in cancer immunotherapy. Nat Rev Cancer. 2012;12(4):252-64.

2. Leach DR, Krummel MF, Allison JP. Enhancement of antitumor immunity by CTLA-4 blockade. Science. 1996;271(5256):1734-6.

3. Selby MJ, Engelhardt JJ, Quigley M, Henning KA, Chen T, Srinivasan M, Korman AJ. Anti-CTLA-4 antibodies of $\operatorname{lgG}_{2}$ a isotype enhance antitumor activity through reduction of intratumoral regulatory $T$ cells. Cancer Immunol Res. 2013;1(1):32-42.

4. Ribas A, Chmielowski B, Glaspy JA. Do we need a different set of response assessment criteria for tumor immunotherapy? Clin Cancer Res. 2009;15(23):7116-8.

5. Wolchok JD, Hoos A, O'Day S, Weber JS, Hamid O, Lebbé C, et al. Guidelines for the evaluation of immune therapy activity in solid tumors: immune-related response criteria. Clin Cancer Res. 2009;15(23):7412-20. 
6. Hodi FS, O'Day SJ, McDermott DF, Weber RW, Sosman JA, Haanen JB, et al. Improved survival with ipilimumab in patients with metastatic melanoma. N Engl J Med. 2010;363(8):711-23.

7. Weber JS, Kähler KC, Hauschild A. Management of immune-related adverse events and kinetics of response with ipilimumab. J Clin Oncol. 2012;30(21):2691-7

8. Bertrand A, Kostine M, Barnetche T, Truchetet ME, Schaeverbeke T. Immune related adverse events associated with anti-CTLA-4 antibodies: systematic review and meta-analysis. BMC Med. 2015;4(13):211.

9. Eggermont AM, Chiarion-Sileni V, Grob JJ, Dummer R, Wolchok JD,

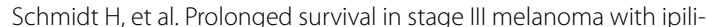
mumab adjuvant therapy. N Engl J Med. 2016;375(19):1845-55.

10. Coens C, Suciu S, Chiarion-Sileni V, Grob JJ, Dummer R, Wolchok JD, et al. Health-related quality of life with adjuvant ipilimumab versus placebo after complete resection of high-risk stage III melanoma (EORTC 18071): secondary outcomes of a multinational, randomised, double-blind, phase 3 trial. Lancet Oncol. 2017;18(3):393-403.

11. Freeman GJ, Long AJ, Iwai Y, Bourque K, Chernova T, Nishimura H, et al. Engagement of the PD-1 immunoinhibitory receptor by a novel B7 family member leads to negative regulation of lymphocyte activation. J Exp Med. 2000;192(7):1027-34.

12. Disis ML. Immune regulation of cancer. J Clin Oncol. 2010:28(29):4531-8.

13. Topalian SL, Hodi FS, Brahmer JR, Gettinger SN, Smith DC, McDermott DF, et al. Safety, activity, and immune correlates of anti-PD-1 antibody in cancer. N Engl J Med. 2012;366(26):2443-54.

14. Robert C, Long GV, Brady B, Dutriaux C, Maio M, Mortier L, et al. Nivolumab in previously untreated melanoma without BRAF mutation. N Engl J Med. 2015;372(4):320-30.

15. Larkin J, Chiarion-Sileni V, Gonzalez R, Grob JJ, Cowey CL, Lao CD, et al. Combined nivolumab and ipilimumab or monotherapy in untreated melanoma. N Engl J Med. 2015;373(1):23-34

16. Weber JS, D'Angelo SP, Minor D, Hodi FS, Gutzmer R, Neyns B, et al. Nivolumab versus chemotherapy in patients with advanced melanoma who progressed after anti-CTLA-4 treatment (CheckMate 037): a randomised, controlled, open-label, phase 3 trial. Lancet Oncol. 2015;16(4):375-84.

17. Weber JS, Kudchadkar RR, Yu B, Gallenstein D, Horak CE, Inzunza HD, et al: Safety, efficacy, and biomarkers of nivolumab with vaccine in ipilimumabrefractory or -naive melanoma. J Clin Oncol. 2013;31(34):4311-8.

18. Gibney GT, Kudchadkar RR, DeConti RC, Thebeau MS, Czupryn MP, Tetteh $\mathrm{L}$, et al. Safety, correlative markers, and clinical results of adjuvant nivolumab in combination with vaccine in resected high-risk metastatic melanoma. Clin Cancer Res. 2015;21(4):712-20.

19. Wolchok JD, Chiarion-Sileni V, Gonzalez R, Rutkowski P, Grob JJ, Cowey $\mathrm{CL}$, et al. Overall survival with combined nivolumab and ipilimumab in advanced melanoma. N Engl J Med. 2017. https://doi.org/10.1056/ NEJMoa1709684.

20. Hodi FS, Chesney J, Pavlick AC, Robert C, Grossmann KF, McDermott DF, et al. Combined nivolumab and ipilimumab versus ipilimumab alone in patients with advanced melanoma: 2-year overall survival outcomes in a multicentre, randomised, controlled, phase 2 trial. Lancet Oncol. 2016;17(11):1558-68.

21. Weber J, Mandala M, Del Vecchio M, Gogas HJ, Arance AM, Cowey CL, et al. Adjuvant nivolumab versus ipilimumab in resected stage III or IV melanoma. N Engl J Med. 2017. https://doi.org/10.1056/NEJMoa1709030.

22. Ribas A, Hamid O, Daud A, Hodi FS, Wolchok JD, Kefford R, et al. Association of pembrolizumab with tumor response and survival among patients with advanced melanoma. JAMA. 2016;315(15):1600-9.

23. Chuk MK, Chang JT, Theoret MR, Sampene E, He K, Weis SL, et al. FDA approval summary: accelerated approval of pembrolizumab for secondline treatment of metastatic melanoma. Clin Cancer Res. 2017. https:// doi.org/10.1158/1078-0432.CCR-16-0663.

24. Taube JM, Klein A, Brahmer JR, Xu H, Pan X, Kim JH, et al. Association of PD-1, PD-1 ligands, and other features of the tumor immune microenvironment with response to anti-PD-1 therapy. Clin Cancer Res. 2014:20(19):5064-74.

25. Taube JM, Young GD, McMiller TL, Chen S, Salas JT, Pritchard TS, et al. Differential expression of immune-regulatory genes associated with PD-L1 display in melanoma: implications for PD-1 pathway blockade. Clin Cancer Res. 2015;21(17):3969-76.
26. Madore J, Vilain RE, Menzies AM, Kakavand H, Wilmott JS, Hyman J, et al. PD-L1 expression in melanoma shows marked heterogeneity within and between patients: implications for anti-PD-1/PD-L1 clinical trials. Pigment Cell Melanoma Res. 2015;28(3):245-53.

27. Festino L, Botti G, Lorigan P, Masucci GV, Hipp JD, Horak CE, et al. Cancer treatment with anti-PD-1/PD-L1 agents: is PD-L1 expression a biomarker for patient selection? Drugs. 2016;76(9):925-45.

28. Friedman CF, Postow MA. Emerging tissue and blood-based biomarkers that may predict response to immune checkpoint inhibition. Curr Oncol Rep. 2016;18(4):21.

29. Mahoney KM, Atkins MB. Prognostic and predictive markers for the new immunotherapies. Oncology (Williston Park). 2014;28(Suppl 3):39-48.

30. Antonioli L, Blandizzi C, Pacher P, Haskó G. Immunity, inflammation and cancer: a leading role for adenosine. Nat Rev Cancer. 2013;13(12):842-57.

31. Ohta A. A metabolic immune checkpoint: adenosine in tumor microenvironment. Front Immunol. 2016;7:109.

32. Allard D, Allard B, Gaudreau PO, Chrobak P, Stagg J. CD73-adenosine: a next-generation target in immuno-oncology. Immunotherapy. 2016;8(2):145-63

33. Wang $R$, Zhang Y, Lin X, Gao Y, Zhu Y. Prognostic value of CD73-adenosinergic pathway in solid tumor: a meta-analysis and systematic review. Oncotarget. 2017:8(34):57327-36.

34. Huang Q, Durham NM, Sult E, Wu Y, Liu J, Holoweckyj N, et al. Levels and enzyme activity of CD73 in primary samples from cancer patients. In: Proceedings of the 106th annual meeting of the American Association for Cancer Research; 2015 Apr 18-22; Philadelphia. AACR; Cancer Res 2015;75 (15 Suppl): p. 1538. https://doi.org/10.1158/1538-7445. AM2015-1538.

35. Hay C, Sult E, Huang Q, Hammond S, Mulgrew K, McGlinchey K, et al. MEDI9447: enhancing anti-tumor immunity by targeting CD73 In the tumor microenvironment. In: Proceedings of the 106th annual meeting of the American Association for Cancer Research; 2015 Apr 18-22; Philadelphia. Philadelphia: AACR; Cancer 2015;75(15 Suppl): p. 285. https://doi. org/10.1158/1538-7445.AM2015-285.

36. Maksimow M, Kyhälä L, Nieminen A, Kylänpää L, Aalto K, Elima K, et al. Early prediction of persistent organ failure by soluble CD73 in patients with acute pancreatitis*. Crit Care Med. 2014;42(12):2556-64.

37. Nedeljkovic N, Bjelobaba I, Subasic S, Lavrnja I, Pekovic S, Stojkov D, et al. Up-regulation of ectonucleotidase activity after cortical stab injury in rats. Cell Biol Int. 2006:30(6):541-6.

38. Caiazzo E, Maione F, Morello S, Lapucci A, Paccosi S, Steckel B, et al. Adenosine signalling mediates the anti-inflammatory effects of the COX-2 inhibitor nimesulide. Biochem Pharmacol. 2016;112:72-81.

39. Geoghegan JC, Diedrich G, Lu X, Rosenthal K, Sachsenmeier KF, Wu H, et al. Inhibition of CD73 AMP hydrolysis by a therapeutic antibody with a dual, non-competitive mechanism of action. MAbs. 2016;8(3):454-67.

40. Balch CM, Gershenwald JE, Soong SJ, Thompson JF, Atkins MB, Byrd DR, et al. Final version of 2009 AJCC melanoma staging and classification. J Clin Oncol. 2009;27(36):6199-206.

41. Sadej R, Spychala J, Skladanowski AC. Expression of ecto-5'-nucleotidase (eN, CD73) in cell lines from various stages of human melanoma. Melanoma Res. 2006;16(3):213-22.

42. Reinhardt J, Landsberg J, Schmid-Burgk JL, Ramis BB, Bald T, Glodde $\mathrm{N}$, et al. MAPK signaling and inflammation link melanoma phenotype switching to induction of CD73 during immunotherapy. Cancer Res. 2017;77(17):4697-709.

43. Sadej R, Spychala J, Skladanowski AC. Ecto-5'-nucleotidase (eN, CD73) is coexpressed with metastasis promoting antigens in human melanoma cells. Nucleosides Nucleotides Nucleic Acids. 2006;25(9-11):1119-23.

44. Wang $\mathrm{H}$, Lee $\mathrm{S}$, Nigro CL, Lattanzio L, Merlano M, Monteverde M, et al. NT5E (CD73) is epigenetically regulated in malignant melanoma and associated with metastatic site specificity. $\mathrm{Br} J$ Cancer. 2012;106(8):1446-52.

45. Young A, Ngiow SF, Madore J, Reinhardt J, Landsberg J, Chitsazan A, et al. Targeting adenosine in BRAF-mutant melanoma reduces tumor growth and metastasis. Cancer Res. 2017:77(17):4684-96.

46. Liu H, Zhang Y, Wu H, D'Alessandro A, Yegutkin GG, Song A, et al. Beneficial role of erythrocyte adenosine $A_{2} B$ receptor-mediated ampactivated protein kinase activation in high-altitude hypoxia. Circulation. 2016;134(5):405-21. 
47. Liu L, Mayes PA, Eastman S, Shi H, Yadavilli S, Zhang T, et al. The BRAF and MEK inhibitors dabrafenib and trametinib: effects on immune function and in combination with immunomodulatory antibodies targeting PD-1, PD-L1, and CTLA-4. Clin Cancer Res. 2015;21(7):1639-51.

48. Sitkovsky M, Ohta A. Targeting the hypoxia-adenosinergic signaling pathway to improve the adoptive immunotherapy of cancer. J Mol Med (Berl). 2013;91(2):147-55.

49. Montinaro A, lannone $\mathrm{R}$, Pinto A, Morello S. Adenosine receptors as potential targets in melanoma. Pharmacol Res. 2013;76:34-40.

50. Sorrentino R, Pinto A, Morello S. The adenosinergic system in cancer: key therapeutic target. Oncoimmunology. 2013;2(1):e22448.

51. Allard B, Longhi MS, Robson SC, Stagg J. The ectonucleotidases CD39 and CD73: novel checkpoint inhibitor targets. Immunol Rev. 2017;276(1):121-44.

52. Sorrentino $C$, Morello $S$. Role of adenosine in tumor progression: focus on $\mathrm{A}_{2} \mathrm{~B}$ receptor as potential therapeutic target. J Cancer Metastasis Treat. 2017:3:127-38.
53. Allard B, Pommey S, Smyth MJ, Stagg J. Targeting CD73 enhances the antitumor activity of anti-PD-1 and anti-CTLA-4 mAbs. Clin Cancer Res. 2013;19(20):5626-35.

54. Mittal D, Young A, Stannard K, Yong M, Teng MW, Allard B, et al. Antimetastatic effects of blocking PD-1 and the adenosine A2A receptor. Cancer Res. 2014;74(14):3652-8.

55. Iannone R, Miele L, Maiolino P, Pinto A, Morello S. Adenosine limits the therapeutic effectiveness of anti-CTLA4 mAb in a mouse melanoma model. Am J Cancer Res. 2014;4(2):172-81.

56. Beavis PA, Milenkovski N, Henderson MA, John LB, Allard B, Loi S, et al. Adenosine receptor $2 \mathrm{~A}$ blockade increases the efficacy of anti-PD-1 through enhanced antitumor T-cell responses. Cancer Immunol Res. 2015;3(5):506-17.

\section{Submit your next manuscript to BioMed Central and we will help you at every step:}

- We accept pre-submission inquiries

- Our selector tool helps you to find the most relevant journal

- We provide round the clock customer support

- Convenient online submission

- Thorough peer review

- Inclusion in PubMed and all major indexing services

- Maximum visibility for your research

Submit your manuscript at www.biomedcentral.com/submit 